\title{
Editorials
}

\section{Fetal and infant origins of adult disease}

The suggestion that certain diseases that usually manifest themselves in middle to late adult life-such as hypertension, ischaemic heart disease, and non-insulin dependent diabetes (NIDDM) - originate in fetal and early infant life seems at first sight highly implausible. To couple this with a challenge to the dogma that these conditions have a genetic basis is perceived by some as outrageous. However, a growing body of evidence, epidemiological and experimental, is consistent with these propositions, perhaps most clearly and strongly when these conditions are combined in the so called "insulin resistance syndrome" or "syndrome $\mathrm{X}$ ".

With the value of hindsight early clues pointing in these directions can now be detected. Rose in 1964 examining familial patterns in ischaemic heart disease observed that the siblings of males who had had a cardiac infarction fared badly, in particular they had an infant mortality rate double that of controls. ${ }^{2}$ Rose warned against jumping to the conclusion that the observed familial aggregation indicated a genetic basis. The relation between infant mortality and subsequent ischaemic heart disease in the survivors of the same generation was first demonstrated by Forsdahl ${ }^{3}$ in a Norwegian study. He suggested that the observation was explained by great poverty in childhood and adolescence followed by prosperity. This finding was duplicated in England and Wales-Barker and Osmond in 1986 proposed that the childhood influences predisposing to ischaemic heart disease were related to poor nutrition during prenatal and early postnatal life that increased susceptibility to the effects of an affluent diet. ${ }^{4}$ In parallel with these observations of relations between ischaemic heart disease and infant mortality, other epidemiological studies detected relations with adult height. In the Whitehall study height was found to be inversely related to mortality from coronary artery disease and it was suggested that factors operating from early life may be important. ${ }^{5}$ NIDDM has also been associated with shortness of stature. ${ }^{6}$

Epidemiological studies in this area in recent years have achieved major advances through the technique pioneered by Barker's research group of identifying populations for whom early anthropometric data are available. It has therefore become possible to examine the relations of a range of adult diseases to indices which give approximate measures of fetal and infant growth. Some key findings have been that males with the lowest weight at birth and at one year had the highest rates of death from ischaemic heart disease; low birth weight and large placentas were associated with the highest blood pressures in adult men and women ${ }^{7}$; impaired glucose tolerance and NIDDM in men fell progressively with increasing birth weight or weight at one year as did blood pressure, possibly indicating factors which cause the association between NIDDM and hypertension. ${ }^{8}$ These observations have been replicated in studies of a variety of populations worldwide.

Thus the strength and reproducibility of the epidemiological data in this area is not in dispute. The current challenge is to provide a mechanistic explanation. Recent research in monozygotic twins discordant for NIDDM showed that the twin with diabetes had a significantly lower birth weight, showing conclusively that non-genetic factors are of major importance. ${ }^{9}$ It has been hypothesised that nutrition, particularly protein nutrition of the mother, may play a major role in determining both the insulin secretion and insulin sensitivity of offspring. ${ }^{10}$ Experiments to test this in a rat model have proved consistent with the hypothesis and have revealed unexpected changes. Groups of pregnant rats fed diets with graded reductions in protein produced offspring which had parallel but inverse changes in blood pressure. ${ }^{11}$ In separate experiments it was found that feeding pregnant rats isocaloric diets containing just under half the normal protein content for the three weeks of pregnancy induced permanent changes in key enzymes of carbohydrate metabolism in the offsprings' liver despite being weaned onto a normal diet. The isolated perfused livers of these mice were insulin resistant and at 15 months animals showed a greater age dependent loss of glucose tolerance. Undoubtedly the effects of growth retardation of the fetus due to restriction of the maternal diet are many and varied, including changes in longevity. ${ }^{12}$

If one reflects upon the key role of fetal life in organogenesis, it becomes less difficult to believe that this period of life may determine the health of organs in middle to late adult life. Although it may appear that the capacity of many organs is surplus to requirements in early to middle life, the reduction of this capacity with age ultimately makes the residual function of key organs critical for survival. Organ growth and development prior to birth have been shown in many studies over many years to be mainly determined by maternal health and nutrition. Since maternal health and nutrition are amenable to improvement it is essential that we test these concepts, however implausible and outrageous they may seem at first sight.

C N HALES

Professor of Clinical Biochemistry

Department of Clinical Biochemistry,

Addenbrooke's Hospital,

Cambridge, United Kingdom

1 Barker DJP, Hales CN, Fall CHD, Osmond C, Phipps K, Clark PMS. Type 2 (non-insulin-dependent) diabetes mellitus, hypertension and hyperlipidaemia (syndrome X): relation to reduced fetal growth. Diabetologia 1993;36:62-7.

2 Rose G. Familial patterns in ischaemic heart disease. British fournal of Preventative and Social Medicine 1964;18:75-80.

3 Forsdahl A. Are poor living conditions in childhood and adolescence an important risk factor for arteriosclerotic heart disease? British fournal of Preventative and Social Medicine 1977;31:91-5.

4 Barker DJP, Osmond C. Infant mortality, childhood nutrition, and ischaemic heart disease in England and Wales. Lancet 1986;i:1077-81

Marmot MG, Shipley MJ, Rose G. Inequalities in death-specific explanations of a general pattern? Lancet 1984;i:1003-6.

6 Brown DC, Byrne CD, Clark PMS, Cox BD, Day NE, Hales CN, et al. Height and glucose tolerance in adult subjects. Diabetologia 1991;34:531-3 Barker DJP, ed. Fetal and infant origins of adult disease. London: BMJ Publishing Group, 1992.

8 Hales CN, Barker DJP, Clark PMS, Cox LJ, Fall C, Osmond C, et al. Fetal and infant growth and impaired glucose tolerance at age 64 years. $B M \mathcal{F}$ 1991;303:1019-22.

9 Vaag A, Populsen P, Kyvik KO, Beck-Nielsen H. Etiology of NIDDM Genetics versus pre- or post natal environments? Results from twin studies. Exp Clin Endocrinol Diabetes 1996;104:181-2.

10 Hales CN, Barker DJP. Type 2 (non-insulin-dependent) diabetes mellitus: the thrifty phenotype hypothesis. Diabetologia 1992;35:595-601.

11 Langley-Evans S, Jackson A. Intrauterine programming of hypertension nutrient-hormone interactions. Nutr Rev 1996;54:163-9.

12 Hales CN, Desai M, Ozanne S, Crowther NJ. Fishing in the stream of diabetes: from measuring insulin to the control of fetal organogenesis. Biochem Soc Trans 1996;24:341-50. 